\title{
O envelhecimento sob a perspectiva da Umbanda: o Arquétipo do velho representado por Orixás e Entidades
}

\author{
Aging from the perspective of Umbanda: the old \\ archetype represented by Orixás and Entities
}

Envejecimiento desde la perspectiva de Umbanda: el viejo arquetipo representado por Orixás y Entidades

Flora Ricciopo Karat Isadora Di Natale Nobre Ruth Gelehrter da Costa Lopes Maria Helena Villas Bôas Concone

RESUMO: Em busca de aprofundamento de algumas das representações do velho na sociedade brasileira, propusemos este trabalho que tem como objetivo estudar o Arquétipo do Velho na perspectiva de uma religião tipicamente brasileira: a Umbanda. Dois Orixás, Nanã Buruquê e Obaluaê, e as Entidades chamadas de Pretos Velhos, são aqueles que melhor representam o Arquétipo do Velho. A própria manifestação corporal de tais energias nos rituais de Umbanda traz, de modo inequívoco, símbolos ligados à velhice. É comum que os participantes dos rituais incorporem conhecimentos simbólicos e significados relativos aos Orixás e Entidades nela cultuados. O Arquétipo do Velho nessa religião representa o conhecimento adquirido ao longo do tempo, as experiências vividas, a sabedoria adquirida, a maturidade e a paciência. Estes são alguns de seus traços mais marcantes. A Umbanda lida com o envelhecimento e o Arquétipo do Velho como elementos essenciais para o processo de evolução da vida e sua importância no processo de individuação de cada um de nós. Neste estudo buscamos fazer uma correlação desse princípio arquetípico com o Arquétipo Puer-Senex da teoria de Carl Gustav Jung. No desenvolvimento da Psicologia Analítica, Jung mostra esse Arquétipo como elemento fundamental para a constituição do sujeito no seu processo de individuação.

Palavras-chave: Arquétipo do Velho; Umbanda; Envelhecimento; Puer-Senex. 
ABSTRACT: In order to deepen some of the representations of the old in Brazilian society, we proposed this work that aims to study the Archetype of the Old from the perspective of a typical Brazilian religion: Umbanda. Two Orixás, Nanã Buruquê and Obaluaê, and the Entities called Old Blacks are the ones that best represent the Old Archetype. The very bodily manifestation of such energies in Umbanda rituals unmistakably carries symbols linked to old age. It is common for ritual participants to incorporate symbolic knowledge and meanings concerning the Orixás and Entities worshiped there. The Old Man Archetype in this religion represents knowledge gained over time, lived experience, acquired wisdom, maturity, and patience. These are some of its most striking traits. Umbanda deals with aging and the Old Archetype as essential elements in the process of life evolution and its importance in the individuation process of each of us. In this study we seek to correlate this archetypal principle with the Puer-Senex Archetype of Carl Gustav Jung's theory. In the development of Analytical Psychology, Jung shows this Archetype as a fundamental element for the constitution of the subject in his individuation process.

Keywords: Archetype of the Old; Umbanda; Aging; Puer-Senex.

RESUMEN: Para profundizar algunas de las representaciones de lo antiguo en la sociedad brasileña, propusimos este trabajo que tiene como objetivo estudiar el Arquetipo de lo Antiguo desde la perspectiva de una religión típica brasileña: Umbanda. Dos Orixás, Nanã Buruquê y Obaluâe, y las Entidades llamadas Viejos Negros son las que mejor representan el Arquetipo Antiguo. La manifestación muy corporal de tales energías en los rituales de Umbanda lleva inequívocamente símbolos relacionados con la vejez. Es común que los participantes en rituales incorporen conocimiento simbólico y significados relacionados con los Orixás y las Entidades adoradas allí. El arquetipo del anciano en esta religión representa el conocimiento adquirido con el tiempo, la experiencia vivida, la sabiduría adquirida, la madurez y la paciencia. Estos son algunos de sus rasgos más llamativos. Umbanda se ocupa del envejecimiento y del arquetipo antiguo como elementos esenciales en el proceso de evolución de la vida y su importancia en el proceso de individualización de cada uno de nosotros. En este estudio buscamos correlacionar este principio arquetípico con el Arquetipo de Puer-Senex de la teoría de Carl Gustav Jung. En el desarrollo de la Psicología Analítica, Jung muestra este Arquetipo como un elemento fundamental para la constitución del sujeto en su proceso de individuación.

Palabras clave: Arquetipo de lo viejo; Umbanda; Envejecimiento Puer-Senex. 


\section{Introdução}

O presente artigo tem como objetivo fazer uma analogia dos aspectos e símbolos do envelhecimento contidos no Arquétipo Puer-Senex, da teoria de Carl Gustav Jung, e vincular as simbologias dessa teoria com os rituais e crenças da religião Umbanda. Para desenvolver essa correlação com o envelhecimento, iremos apresentar dois Orixás: Nanã Buruquê e Obaluaê, e uma Entidade: Preto Velho. Finalizaremos através de considerações sobre as similaridades do material proposto: envelhecimento e Umbanda.

\section{Envelhecimento}

O Envelhecimento na contemporaneidade - principalmente em uma perspectiva ocidental - é um tema causador de angústia, devido a seu envolvimento com questões desconhecidas do ciclo vital da finitude do ser humano, junto à ausência de visões multidimensionais vinculadas a esta fase do desenvolvimento humano. "A finitude, na verdade, traz angústia ao ser humano, a angústia diante de uma instância desconhecida, a que ele deve inexoravelmente se submeter como uma grande punição ou expiação de uma culpa original" (Rezende, Lodovici, \& Concone, 2012, p. 50). Em uma sociedade que compactua com o "não envelhecer", em que o "envelhecimento permaneceu na orla social por tanto tempo como uma espécie de tabu, da ordem de um interdito em relação ao qual o silencia seria o melhor aliado" (Correa, 2009, p. 28), perde-se a possibilidade de considerar essa fase como um processo de transformação da própria idade e consciência pessoal, em que novos valores podem ser adotados (Côrte, Mercadante, \& Arcuri, 2005). Carl Gustav Jung (1972) teoriza e ilustra essa nova etapa como Metanoia ${ }^{1}$. Designa essa fase como a segunda fase da vida, seguindo os caminhos para a evolução e o desenvolvimento de um indivíduo, traçando um redimensionamento da consciência em direção ao mundo interno. "O direcionamento que se dá em direção ao Self aponta para a possibilidade de vivenciar os aspectos transcendentes do Ser. Principalmente ao se deparar com o declínio das forças físicas, muitas vezes, pode se experimentar as fontes inexauríveis de criatividade desse centro chamado Self'" (Arcuri, 2012, pp. 89-90).

\footnotetext{
${ }^{1}$ Metanoia: “(...) termo grego que indica a transformação da própria identidade pessoal, depois de uma experiência que transforma os valores até então adotados por um indivíduo(...). Um conceito que não tem conotação rigidamente cronológica(...). (Gaeta, \& Arcuri, 2016, p. 44).
} 
Independentemente da forma, da qualidade e do aspecto cultural do processo do envelhecimento, todos envelheceremos. Diferentes são as maneiras de vivenciar essa transformação, mas o fato de todos seguirem a caminho de um princípio semelhante torna o envelhecer um fenômeno cultural e arquetípico. Cultural, pois apresenta seus atributos simbólicos específicos do que é o envelhecer, de acordo com o que é cultuado e adquirido na relação geracional de determinado povo ((Côrte, Mercadante, \& Arcuri, 2005); e arquetípico, por todos seguirem um determinado padrão advindo do que está constituído no inconsciente coletivo, junto com as questões singulares e pessoais de cada indivíduo (Arcuri, 2012).

$\mathrm{Na}$ teoria analítica, o arquétipo é um elemento fundamental, que nos serve como guia para nos aprofundarmos no entendimento da alma humana, a caminho do processo de individuação. Para Jung, uma forma de alcançar o entendimento sobre as dimensões e conteúdos contidos nos arquétipos é através da análise e leitura aprofundada dos símbolos que a natureza, os mitos, a mitologia, e os sonhos podem nos fornecer, partindo do princípio de que esses conceitos estão para além do domínio consciente da psique do ser humano, por fazerem parte da amplitude do inconsciente coletivo.

Por meio da interpretação aprofundada dos símbolos e signos emitidos pela natureza e abordados nos mitos, é possível adquirir explicações sobre os principais acontecimentos da vida; "vemos que todas as culturas têm seus mitos, muitos dos quais são expressões particulares de arquétipos comuns a toda a humanidade. Assim sendo, os mitos são formas de expressões dos arquétipos, falando daquilo que é comum aos homens de todas as épocas" (Mello, 2016, p.17). Os mitos, muitas vezes vinculados a aspectos religiosos, nos auxiliam a tomadas de consciência sobre as maneiras e padrões humanos em suas diferentes fases da vida. A tomada desses princípios arquetípicos pela consciência tem grande valor para as etapas da vida de cada um, diante da maneira como cada um, individualmente, irá entrar em relação com seu desenvolvimento pessoal. Ainda sobre este aspecto arquetípico, Eliade (1992) aponta sobre a importância de o homem procurar e associar os aspectos simbólicos obtidos pela consciência, pois ele só se reconhece como um ser psíquico, de fato, quando é comparado aos deuses, os heróis e seus antepassados.

Jung utiliza-se dos arquétipos Puer e Senex como polaridades arquetípicas - o jovem e o velho - sem estabelecer uma ligação com a idade cronológica de um indivíduo. Juntos possibilitam o equilíbrio para a psique, servindo como possibilidade 
de transformação do que é velho em busca de um amadurecimento. "Uma consciência ampliada é instrumento fundamental para a autonomia do homem, uma vez que, dessa maneira, ele se desvencilha da mente coletiva e, assim, tem condições de discriminar e de fazer escolhas mais autênticas, gerenciadas por suas reais necessidades" (Monteiro, 2008, p. 100). Vivenciar esses aspectos arquetípicos separadamente seria um equívoco para a dinâmica da psique. Ambos apresentam suas características negativas e positivas, que, em comunhão, se articulam a caminho do desenvolvimento. "A ativação do eixo Puer-Senex tem função vital na maturidade e na velhice; é ele que nos distanciará dos aspectos negativos do velho senil, inserindo-nos na vivência da sabedoria ao envelhecer"' (Monteiro, 2008, p. 58).

$\mathrm{O}$ arquétipo do Puer é representado com a criança divina, simboliza um novo espírito, advindo de um espírito velho, com a meta de promover transformações na visão do mundo, "há, nele, uma grande resistência em se prender e de fazer parte das questões objetivas que envolvam tempo e espaço" (Monteiro, 2008, p. 103). Possui aspectos próprios dessa fase como: apegos a seus bens, busca pela liberdade, rapidez, plasticidade adaptativa, força física, ilusões narcísicas, negação da morte, vivendo sempre em busca de expansão no mundo externo, criatividade, espontaneidade e inocência. Esses símbolos caracterizam o início de um novo ciclo de vida, com a energia voltada para o futuro, para a renovação da vida, mas ao mesmo tempo ligada com o passado.

$\mathrm{Na}$ visão contemporânea da velhice, essas características do jovem em relação ao velho são vistas equivocadamente. O "ser velho" constitui-se de forma antagônica ao "ser jovem", causando, inclusive, pontos de vista estigmatizados e negativos do envelhecer. À ausência de uma visão simbólica sobre a polaridade abordada por Jung Puer-Senex ${ }^{2}$ - na tratativa do velho, a sociedade ocidental dos últimos tempos desqualifica as características fundamentais regentes nessa fase. Não sem razão, Mercadante (2005, p. 32) ressalta: "São essas ideias, relacionando velhice e tempo, que apontam para um velho que não investe no presente, nem projeta para o futuro.

\footnotetext{
2 A respeito do termo Senex, os articulistas, Katzenstein, Schwartz, \& Almeida (2012, p. 203), lembram que: "Conforme conceito de Carl Jung, etimologicamente esse termo latino é usado para designar adultos e anciãos, chefes de família, com posto político no Senado.
} 
Essas ideias conformam uma noção de idoso que só tem passado, lembranças para rememorar e, no futuro, o confronto com a morte"; "perdendo-se, assim, de vista o poder que se tem de ressignificar o sentido da vida, em transformação para um novo ciclo, visto que a velhice não é estática, mas sim dinâmica. "Puer e Senex regeneram-se constantemente; o velho espírito é substituído pelo espírito novo" (Bernardi, 2008, p. $32)$.

Com a tendência em obter uma visão unilateral desse arquétipo, perde-se e desqualificam-se as contingências do ponto de vista do arquétipo Senex, visto somente como "o velho". Sabedoria, força espiritual, apresentação com a morte, autotrancendência, expansão com o mundo interno - Self, conservação (p. 59) são algumas das particularidades que caracterizam esse arquétipo. Além da sua ambiguidade em relação ao Puer, sendo o velho sábio, silencioso, sábio solitário, com uma forte ligação com a morte, que muitas vezes assusta o Puer (p. 39).

Como dito anteriormente, entrar na fase da Metanoia, em todos os seus aspectos transitórios, causa angústia pelo desconhecido, levando o indivíduo a seguir em busca por respostas no universo simbólico, muitas vezes optando por caracteres religiosos que expliquem esses "buracos negros", a fim de reorganizar a estrutura psíquica do ser humano e seu entorno.

"Buscar o ambiente religioso representa a atribuição de sentidos às demandas impostas pela vida cotidiana, inclusive à própria morte que se pacifica, e permitir caminhos para melhoria da situação de angústia diante de sua incidência” (Rezende, Lodovici, \& Concone, 2012, p. 51). ${ }^{3}$

Para ilustrar tal questão, citaremos alguns aspectos da religião da Umbanda, através de suas metáforas e símbolos, visando a ampliar o sentido arquetípico da vivência do ser humano diante de suas etapas e revelar características ritualísticas que resumem sua relação com o processo do envelhecimento e os arquétipos mencionados.

\footnotetext{
3 "Therefore, seeking the religious environment represents the attribution of meaning to the demands imposed by everyday life - including death which is made peaceful - while finding ways to soothe the feeling of anguish once it arise." (de tradução dos mesmos autores para o português). 


\section{Umbanda}

\section{Histórico}

A Umbanda pode ser considerada uma religião brasileira (Vaini, 2006, p. 18) que tem sua origem influenciada por diversas culturas religiosas, como as práticas nativas dos índios, os cultos africanos, o Catolicismo e a doutrina espírita Kardecista (Cumino, 2011, pp. 33-79). Cada uma delas traz importantes elementos a sua prática, como a comunicação com o plano espiritual, o sincretismo com os santos católicos, o culto à natureza por meio de divindades, o uso das ervas, defumação, entre outros.

A Umbanda tem como principal objetivo possibilitar a conscientização e o desenvolvimento dos princípios e virtudes espirituais, tornando as pessoas mais espiritualizadas e menos materialistas (Moreno, 2011, p. 57). A partir de ensinamentos e vivências, a religião propicia o desenvolvimento do autoconhecimento, a ampliação da consciência e, portanto, a transformação interna de cada um, de seu meio consequentemente.

Os rituais magísticos e a relação com a natureza são algumas das maneiras para entrarmos em contato com os valores espirituais e trabalharmos nosso interior. Nos rituais a religião se utiliza de espíritos de luz que trazem mensagens, visando a orientar sobre como podemos viver a nossa vida mais plena e conectada, de forma a alcançarmos a evolução espiritual individual e coletiva.

\section{Orixás e Entidades}

Os Orixás são as divindades cultuadas na religião, constituindo-se como energias que estão ligadas a um campo de atuação na natureza (Saraceni, 2012, p. 33) e da mesma forma possuem correlação com qualidades como a sabedoria, a justiça, a fé, o amor. Cada Orixá traz em si energias arquetípicas que possibilitam o desenvolvimento de nosso psiquismo. Do mesmo modo com que a psicologia junguiana se utiliza de símbolos como acesso aos arquétipos, a Umbanda se vale das divindades e seus atributos como acesso aos elementos da natureza. 
Cultuar os Orixás está para além da religião em si. Eles estão ligados a manifestações arquetípicas, à cultura, à psicologia e à alteridade. Santos e Pereira (2012) apontam que "outra categoria que caberia incluir nessa introdução seria a alteridade (relação com o outro e com a natureza - Orixás - expressa pelo ritual, dança em roda/círculo e que remete a uma rememoração da ancestralidade na memória mítica que é ali celebrada) (2012, p. 17).

As Entidades ou Guias são espíritos de luz que trabalham na Umbanda, se apresentando dentro de determinada linha de trabalho. Cada uma destas é regida pela vibração de determinados Orixás em suas diferentes linhas de atuação junto às forças da natureza.

\section{Nanã Buruquê}

Uma das lendas desse Orixá conta que, quando Oxalá recebeu ordens de Olorum (Deus Supremo) para criar o homem, utilizou, sem sucesso, de várias matérias-primas. Tentou o ar, mas o homem se desfez rapidamente. Experimentou a madeira, mas o homem ficou muito duro. O mesmo, e com mais intensidade, aconteceu com a pedra. Com o fogo, nada feito, pois o homem se consumiu. Oxalá tentou outros elementos, como água e azeite. Nada funcionava. Então, Nanã veio em seu socorro, com seu Ibiri, apontou para o fundo do lago onde ela morava e de lá retirou a lama que entregou a Oxalá para ele fazer o homem. Deu certo: o homem foi modelado de barro e, com o sopro de Olorum, ganhou vida. Com a ajuda dos Orixás povoou a terra. Mas em um dia o homem morre e seu corpo tem que retornar a terra, voltar à natureza de Nanã, que deu a matéria no começo, mas quer de volta, no final, tudo o que é seu (Prandi, 2001, p. 196).

Nanã Buruquê é um Orixá muito antigo (Verger, 2002, p.236), a mais velha das divindades das águas (Iabás), considerada avó de todos os Orixás (Scipioni, \& Correa, 2008, p.137); seu culto na África se estende a várias regiões. Nanã é a velha senhora, associada ao elemento água em contato com a terra; por isso, seu ponto de atuação na natureza concentra-se nos lagos, lodos, pântanos e na chuva mansa que irriga a terra. (Barcellos, 2012, p.121). É a mais temida e respeitada de todos os Orixás. Senhora da morte é a responsável pela passagem desta vida para outras dimensões (Saraceni, 2002, p. 99), ligada ao princípio e ao fim de tudo. Está associada à evolução dos seres, é a 
detentora da sabedoria de vida, é a possibilidade de se conhecer a morte para se ter a vida.

Sua terra se transforma em lama e é da terra que nasce o ser humano e para a terra é que somos levados ao morrer: é a Grande Mãe, de onde tudo nasce e tudo retorna. Quando estamos para encarnar, é Ela que decanta o espírito, adormece as memórias mentais e reminiscências de vidas passadas, preparando-o para uma nova vida na carne. Tem o poder de libertar o passado, propiciando o esquecimento para iniciar um novo ciclo, direcionando-se para o futuro.

Representa a força que nos ajuda a entrar no silêncio, na serenidade de nossas emoções, a desapegar de nossos vícios e a desenvolver a paciência e a tolerância para lidarmos com nosso cotidiano. Traz o acolhimento, o saber ouvir e respeitar o tempo subjetivo de cada um. Possibilita a reforma interior de nosso ser, o equilíbrio emocional e mental. Nanã possui o poder da cura espiritual, nos transformando conforme nossas necessidades de crescimento espiritual, trazendo a evolução de nossas almas. Tem na mão, como instrumento, o Ibiri para afastar a morte, símbolo que traz a união das polaridades vida-morte, princípio-fim (Scipioni, \& Correa, 2008, pp.137-141).

\section{Omolu/Obaluaê/Xapanã}

Uma lenda conta que, chegando de viagem à aldeia onde nascera Xapanã, viu que estava acontecendo uma festa com a presença de todos os Orixás. Obaluaê não podia entrar na festa, devido à sua medonha aparência. Então, ficou espreitando pelas frestas do terreiro. Ogum, ao perceber a angústia do Orixá, cobriu-o com uma roupa de palha, com um capuz que ocultava seu rosto doente, e convidou-o a entrar. Apesar de envergonhado, Obaluaê entrou, mas ninguém se aproximava. Iansã tudo acompanhava com o rabo do olho; compreendia a triste situação e dele se compadecia. Iansã esperou que ele estivesse bem no centro do barracão. A festa estava animada. Os Orixás dançavam alegremente. Iansã chegou então bem perto e soprou suas roupas de palha com seu vento. Nesse momento de encanto e ventania, as feridas de Obaluaê pularam para o alto, transformadas numa chuva de pipocas, se espalhando brancas pelo barracão. Obaluaê, o Orixá das doenças, transformara-se num jovem belo e encantador (Scipioni, \& Correa, 2008, p. 111). 
Omolu, Obaluaê ou Xapanã são forças divinas que apresentam as mesmas características. Diz-se que a forma jovem é Obaluaê; e Omolu, a forma mais velha, o sábio feiticeiro (Barcellos, 2012, p. 86). Ambos têm a mesma regência e podem ser considerados a mesma força da natureza. Possuem ligação direta com Nanã Buruquê; em algumas regiões da África são cultuados como sendo a mesma divindade (Verger, 2002, p. 214).

Obaluaê atua na evolução, cuida das passagens dos estágios da vida. Assim como Nanã, é o senhor das passagens de uma dimensão para outra. Ele estabelece o cordão energético que une o espírito ao corpo. É o Orixá que rege a morte, o regente dos cemitérios, trabalha na condução dos espíritos para o ingresso na vida depois do desencarne (Saraceni, 2002, p. 90). Ligado ao elemento terra é o responsável por nos conectar com a realidade material.

Também comanda as doenças e, consequentemente, a saúde; é o curador divino, tanto da alma ferida quanto do corpo doente. Seu instrumento Xaxará é usado tanto para propagar, quanto afastar, e curar as doenças. Cobre o seu rosto com palhas devido à deformação causada pela doença. Traz, dessa forma, a integração entre os opostos saúde-doença, despertando o conhecimento de que tais opostos pertencem a um mesmo processo e arquétipo, inseparáveis.

\section{Pretos Velhos}

São Entidades que possuem, como arquétipo, o símbolo do ex-escravo, catequizado. Nem todos foram escravos e negros em sua encarnação, mas se utilizam desse arquétipo para transmitirem suas mensagens. Possuem, como características mais marcantes, a humildade, a simplicidade, a resignação, a fé e o amor. Detentores de muita sabedoria, que fora adquirida através de suas experiências de vida, são espíritos que cresceram com o sofrimento e aprenderam a perdoar; hoje representam a força e a capacidade de resistir e superar os obstáculos da vida. Trazem como símbolo a sabedoria do velho, do simples ancião que nos ensina a nunca perdermos a fé e a esperança, possibilitando a transformação de nossas dores em crescimento espiritual. Também ensinam a desenvolvermos a paciência ao lidar com nossos semelhantes, a nunca julgar, mas compreender que cada um tem o seu tempo próprio de evolução. 
Esta linha de trabalho é sustentada pelos Orixás Obaluaê e Nanã Buruquê, o que significa que, em sua essência, trarão as características desses Orixás como a sabedoria, a maturidade, a transmutação e o equilíbrio da alma. Sua energia é serena e suas palavras nos acolhem com amor, sempre têm conselhos que ensinam os reais valores da vida, despertando a humildade e a caridade em nossos corações (Saraceni, 2012, p. 96). Possuem muita afinidade com a linha dos Erês (Crianças) que normalmente são acompanhadas por um Preto Velho como uma figura que as guia e aconselha.

\section{Considerações}

A partir dos conceitos apresentados, podemos concluir que a Umbanda considera o envelhecimento como sendo uma fase de vida e polo essencial ao desenvolvimento humano e da evolução espiritual. As características dos Orixás e Entidades que trazem conteúdos arquetípicos do ser velho representam a importância de tal elemento em nossas vidas. A manifestação corporal de tais energias, como o lento caminhar, a postura curvada mais próxima ao chão (Concone, 2006, p.11), a expressão serena constituem símbolos que podem ser, de algum modo, correlacionados com a fase da Metanoia, apresentada por Jung como a etapa da vida em que vivemos processos de introspecção e ampliação de nossa vida psíquica, voltada aos aspectos transcendentes do ser, o Self.

Muitos Pretos Velhos permanecem sentados durante o ritual e utilizam aditamentos como bengalas para caminhar, representando o cansaço, o limite do corpo, advindos com o passar do tempo e, dessa forma, fazem a correlação entre saúde e doença, como sendo polos de um mesmo processo pois, ao mesmo tempo, em que a fragilidade do corpo aparece, é ela própria a detentora da potência psíquica e da sabedoria de vida, espiritual.

Ao nos aprofundarmos no conhecimento dos Orixás e Entidades mencionadas, nos deparamos com elementos que simbolizam a integração dos opostos como criançavelho, princípio-fim, doença-saúde, morte-vida.

No Brasil, o reinante pluralismo religioso oferece múltiplas vias ao indivíduo de lhe permitir uma concepção significativa da realidade e de sua visão de mundo, aliando-o do sofrimento e da dor, diante do imponderável e da morte. É preciso que se reconheça o sentido da 
morte para que se possa reconhecer também o sentido da Vida, e ao mesmo tempo em que se pense em atitudes adequadas diante da Vida, que se pense também na "construção de atitudes diante da morte" (Rezende, Lodovici, \& Concone, 2012, p. 51).

Tais elementos, por sua vez, remetem-nos a natureza arquetípica da polaridade contida no Puer e Senex, ao pensarmos que é necessário ao velho passar pelo período de transformação em busca do novo, e ao jovem, com as reminiscências advindas com o velho, seguir sua trajetória com maior aptidão e sabedoria.

A apresentação desses arquétipos pela Umbanda permite-nos concluir que o envelhecimento vivido sob a perspectiva dessa religião é representado como detentor de um valor insubestimável: a sabedoria da vida e de seus processos. Podemos afirmar, dentro destes preceitos, que o envelhecimento é a fase da vida que possibilita o desenvolvimento da maturidade psíquica e espiritual.

\section{Referências}

Arcuri, I. P. G. (2012). Velhice e Espiritualidade: Metanoia, "A segunda metade da vida", segundo Carl Gustav Jung. Revista Kairós-Gerontologia, 15(3), 87-104. ISSNprint 1516-2567. ISSNe 2176-901X. São Paulo, SP, Brasil: PUC-SP. Recuperado em 10 junho, 2017, de: file:///C:/Users/Dados/Downloads/13797-33217-1-SM.pdf.

Bernardi, C. (2008). Senex et Puer: esboço da psicologia de um arquétipo. (Puer-senex: dinâmicas relacionadas. Coleção Reflexões Junguianas). Petrópolis, RJ: Vozes.

Barcellos, M. C. (2012). Os Orixás e o Segredo da Vida: lógica, mitologia e ecologia. (5 ed.). Rio de Janeiro, RJ: Pallas.

Concone, M. H. V. B. (2006). O ator e seu personagem. Revista Nures, Edição Ano 2(4), pp. 01-34, "Diversidade, Corpo e Religião", (set./dez.2006). Publicação eletrônica do Núcleo de Estudos Religião e Sociedade PUC-SP, São Paulo, SP. ISSN: 1981-156X. Recuperado em 10 junho, 2017, de: https://www.pucsp.br/revistanures/revista4/nures4_mariahelena.pdf.

Correa, M. R. (2009). Cartografias do envelhecimento na contemporaneidade: velhice e terceira idade. São Paulo: Editora UNESP; Cultura Acadêmica. (125p.). ISBN 978-857983-003-7. Recuperado em 10 junho, 2017, de: SciELO Books< http://books.scielo.org.

Côrte, B., Mercadante, E. F., \& Arcuri, I. G. (Orgs.). (2005). Velhice. Envelhecimento Complex(idade). São Paulo, SP: Vetor Psico-Pedagógico Ltda.

Cumino, A. (2011). História da Umbanda: uma religião brasileira. São Paulo, SP: Madras.

Eliade, M. (1992). O sagrado e o profano. São Paulo, SP: Martins Fontes. 
Gaeta, I., \& Mendes, D. C. (2016). Velhice e Metanoia - Uma análise do filme Hanami: cerejeiras em flor. Revista Kairós-Gerontologia, 19(2), pp. 41-63. ISSNprint 15162567. ISSNe. 2176-901X. São Paulo, SP, Brasil: PUC-SP. Recuperado em 10 junho, 2017, de: file:///C:/Users/Dados/Downloads/29984-79587-2-PB\%20(2).pdf.

Jung, C. G. (1942). O eu e o inconsciente. Inconsciente Pessoal e Inconsciente Coletivo. [1934, or.]. In: Obras completas, v. 7. Petrópolis: Vozes, 1981.

(2000). Os arquétipos e o inconsciente coletivo. Petrópolis, RJ: Vozes.

(2014). Sobre sonhos e transformações: sessões de perguntas de Zurique /

C. G. Jung. Lorena Richter, Trad. Petrópolis, RJ; Vozes.

Katzenstein, T., Schwartz, G., \& Almeida, M. H. M. de. (2012). Reflexões sobre aproximação de idosos a tecnologias de informação e comunicação a partir dos arquétipos Senex e Puer. Revista Kairós-Gerontologia, 15(3), 203-218. ISSNprint 15162567. ISSNe 2176-901X. São Paulo, SP, Brasil: PUC-SP. Recuperado em 10 junho, 2017, de: file:///C:/Users/Dados/Downloads/9883-33266-1-PB\%20(3).pdf.

Mello, L. T. de (2016). O Envelhecer: uma análise junguiana na mitologia africana. Dissertação de mestrado em Gerontologia. Programa de Estudos Pós-Graduados em Gerontologia. São Paulo, SP: Pontifícia Universidade Católica de São Paulo. (97p.). Recuperado em 10 junho, 2017, de: https://tede2.pucsp.br/bitstream/handle/12469/1/Leonardo\%20Tondato\%20de\%20Mello.pdf.

Monteiro, D. M. R. (2008). Puer-senex: dinâmicas relacionadas. Petrópolis, RJ: Vozes.

Moreno, S., \& Feitosa, C. (Orgs.). (2011). Mensageiros da Espiritualidade: o despertar da humanidade para um novo momento. São Paulo, SP: PerSe.

Prandi, R. (2001). Mitologia dos Orixás. São Paulo, SP: Companhia das Letras.

Rezende, E. G., Lodovici, F. M. M., \& Concone, M. H. V. B. (2014). Infinitude in Religion: When one life is not enough. Revista Temática Kairós-Gerontologia, 17(Special Number, 17), Thematic Issue: "Death/Finitude and Old Age", pp. 181-197. Print ISSN 1516-2567. ISSNe 2176-901X. São Paulo, SP, Brasil: PUC-SP.

Santos, R. A. dos, \& Pereira, K. M. de A. (2012). Os mitos africanos e a lírica de protesto na poesia contemporânea de Waldo Motta. Revista Texto Poético, 8(12), pp. 94-106. ISSN 1808-5385. Recuperado em 10 junho, 2017, de: file:///C:/Users/Dados/Downloads/93-161-1-SM.pdf.

Saraceni, R. (2002). Umbanda Sagrada: Religião. Ciência, Magia e Mistérios. (2a ed.). São Paulo, SP: Madras.

Saraceni, R. (2012). Os arquétipos da Umbanda: as hierarquias espirituais dos Orixás. São Paulo, SP: Madras.

Scipioni, S., \& Correa, D. (2008). Os Orixás e os Chacras. Porto Alegre, RS: Besouro Box.

Verger, P. F. (2002). Orixás - Deuses Iorubás na África e no Novo Mundo. Maria Aparecida da Nóbrega, Trad. (6 $6^{\mathrm{a}}$ ed.). Salvador, BA: Corrupio.

Vaini, S. V. (2006). Um olhar sobre a Umbanda: memória e aprendizagem num terreiro de São Paulo. Revista Espaço Plural, 7(14), pp. 18-19. (Ano VI, $1^{\circ}$ semestre). ISSN: 1981-478X. Recuperado em 10 junho, 2017, de: file:///C:/Users/Dados/Downloads/4861684-1-PB.pdf. 
Recebido em 20/01/2019

Aceito em 30/03/2019

Flora Ricciopo Karat - Psicóloga, Graduada em Psicologia, Pontifícia Universidade Católica de São Paulo, PUC-SP. Mestra, Programa de Estudos Pós-Graduados em Gerontologia/FACHS/PUC-SP. Formação em Acompanhamento Terapêutico (AT), atuando na área de Psicogerontologia. Atua na psicologia clínica voltada ao atendimento de adolescentes, adultos e idosos. Desenvolve pesquisa em psicologia do envelhecimento.

E-mail: fkarat@gmail.com

Isadora Di Natale Nobre - Psicóloga, Pontifícia Universidade Católica de São Paulo (PUC-SP). Mestra no Programa de Gerontologia, concentração em Psicologia Social/PUC-SP. Formação em Acompanhamento Terapêutico (AT), atuando em Saúde Mental, Reabilitação física e Psicogerontologia. Aperfeiçoamento em Reabilitação na Deficiência Física: Enfoque Multidisciplinar pela Associação de Assistência à Criança Deficiente (AACD). Trabalha no setor de Psicologia Adulto da AACD desde 2014. E-mail: isadora_nobre@hotmail.com 
Maria Helena Villas Bôas Concone - Doutora em Antropologia, PUC-SP. Graduada em Ciências Sociais, USP. Profa. Titular do Departamento de Antropologia, Faculdade de Ciências Sociais/PUC-SP. Docente, Pesquisadora, Orientadora, nos Programas de Estudos Pós-Graduados em Ciências Sociais, PUC-SP e em Gerontologia/FACHS/PUC-SP. Membro do Comitê de Ética em Pesquisa, Secretaria Municipal da Saúde de São Paulo, até 2011 e na PUC-SP, desde 2015. Palestrante convidada para temas relacionados à Saúde/Doença, Envelhecimento e Velhice, Religião e Religiosidade, Ética em Pesquisa, Interdisciplinaridade. Publicações sobre os temas de Ética em Pesquisa, Religião e Religiosidade Brasileira, Religiões AfroBrasileiras, Cura e Visão de Mundo, Envelhecimento e Velhice, Noção de Cultura, Educação e Cultura, Mídia e Religião, Velhice na Mídia, Morte e Finitude. Parecerista na FAPESP e ad hoc de diversas revistas indexadas, Parecerista do PBIC e Bolsas "Sanduíche" em unidades da PUC-SP.

E-mail: mhconcone@yahoo.com.br

Ruth Gelehrter da Costa Lopes - Doutora em Saúde Pública, USP. Psicóloga. Docente, Pesquisadora, Orientadora da Pontifícia Universidade Católica de São Paulo (PUC-SP), no Programa de Estudos Pós-Graduados em Gerontologia, e no Curso de Psicologia e Supervisora na Clínica-Escola “Ana Maria Poppovic”. Coordenadora do grupo de pesquisa certificado pelo CNPq: Núcleo de Estudo e Pesquisa do Envelhecimento-NEPE. Membro da Red Iberoamericana de Psicogerontologia (Redip).

E-mail: ruthgclopes@ pucsp.br 